\title{
MASTER COPY
}

\section{MAR 281989}

ORNL/NRC/LTR-89/3

Engineering Technology Division

\section{A REVIEW AND ASSESSMENT OF MATERTALS PROPERTY DATABASES WITH PARTICULAR REFERENCE TO CONCREIE MATERIAL SYSTEMS}

M. F. Marchbanks

March 1989

\author{
Prepared for the \\ U.S. Nuclear Regulatory Commission \\ Office of Nuclear Regulatory Research \\ Under Interagency Agreement No. 1886-8084-5B
}

NRC ETN No. B08459

\author{
Prepared by the \\ OAK RIDGE NATIONAL LABORATORY \\ Oak Ridge. Tennessee 37831 \\ operated by \\ MARTIN MARIETTA ENERGY SYSTEMS, INC. \\ for the \\ U.S. Department of Energy \\ under Contract No. DE-ACO5-84OR21400
}


CONIENTS

Page

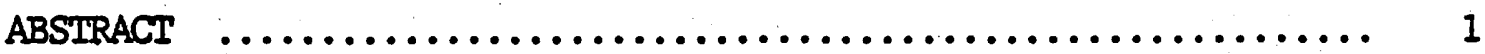

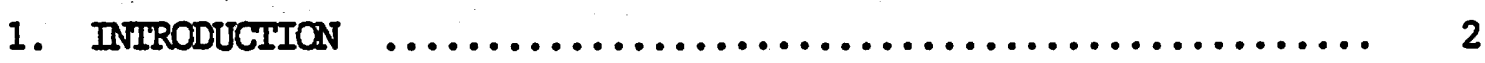

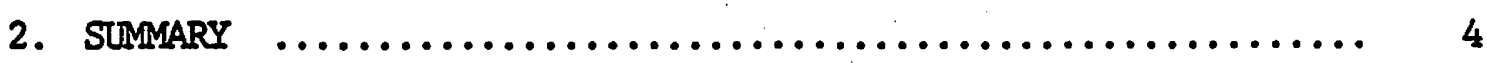

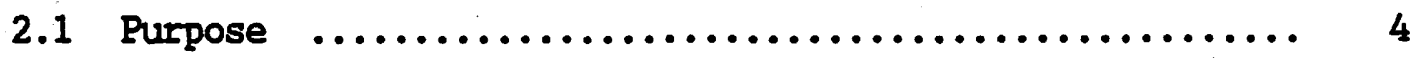

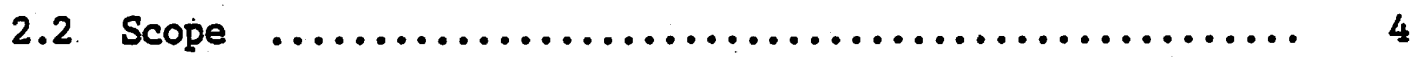

2.2.1 Database Management Systems $\ldots \ldots \ldots \ldots \ldots \ldots \ldots . \ldots 4$

2.2.1.1 Database Management Systems

2.2.1.2 Database Management Systems Software

Classification $\ldots \ldots \ldots \ldots \ldots \ldots \ldots \ldots \ldots$

3. REVIEW RESULTS AND ASSESSMENTS $\ldots \ldots \ldots \ldots \ldots \ldots \ldots \ldots \ldots \ldots$

3.1 Database Management Systems Software Reviews .......... 7

3.1.1 Mainframe Database Management Sysțems ........ 7

3.1.1.1 TIRGES ..................... 7

3.1 .1 .2 SPIRES $\ldots \ldots \ldots \ldots \ldots \ldots \ldots \ldots \ldots \ldots \ldots \ldots$

3.1.1.3 MESSENGER $\ldots \ldots \ldots \ldots \ldots \ldots \ldots \ldots \ldots \ldots \ldots$. 8

3.1 .1 .4 ORACTE $\ldots \ldots \ldots \ldots \ldots \ldots \ldots \ldots \ldots \ldots \ldots . \ldots . \ldots$

3.1.2 PC Database Management Systems $\ldots \ldots \ldots \ldots \ldots \ldots$

3.1.2.1 ORACLE $\ldots \ldots \ldots \ldots \ldots \ldots \ldots \ldots \ldots \ldots \ldots . \ldots \ldots$

3.1 .2 .2 INGRES $\ldots \ldots \ldots \ldots \ldots \ldots \ldots \ldots \ldots \ldots \ldots \ldots \ldots . \ldots 10$

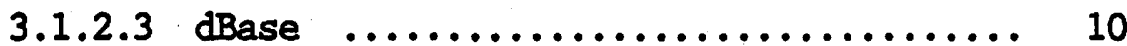

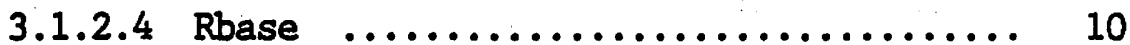

3.1.2.5 MetSe12 and MatDB ............... 11

3.2 Database Reviews $\ldots \ldots \ldots \ldots \ldots \ldots \ldots \ldots \ldots \ldots \ldots \ldots \ldots \ldots . \ldots \ldots$

3.2.1 Computerized Databases $\ldots \ldots \ldots \ldots \ldots \ldots \ldots \ldots \ldots \ldots$

3.2.1.1 Mainframe Materials Databases ........ 11

3.2.1.1.1 Waste Information

Network (WIN) ........... 12

3.2.1.1.2 Safety Analysis

Computerized Reactor

Data (SACRD) ........... 12

3.2.1.1.3 National Materials

Property Data Network

(MPD Network) ........... 13

3.2.1.1.4 Radiation Shielding

Information Center

(RSIC) $\ldots \ldots \ldots \ldots \ldots \ldots \ldots \ldots . . . . .14$

3.2.1.1.5 Construction Engineering

Research Laboratory

(CERL) ................. 14 
Page

3.2.1.1.6 Metals and Ceramic

Information Center

(MCIC) $\ldots \ldots \ldots \ldots \ldots \ldots \ldots, 14$

3.2.1.1.7 Mechanical Properties

Data Center (MPDC) ........ 15

3.2.1.1.8 U.S. Coast Guard Database

(MARTUF) ............... 15

3.2.1.1.9 European Materials Infor-

mation Services Network

(EMISN) $\ldots \ldots \ldots \ldots \ldots \ldots, 15$

3.2.1.1.10 Institut für Massivbau and

Baustofftechnologie ....... 16

3.2.1.1.11 University of Tokyo $\ldots \ldots \ldots .16$

3.2.1.1.12 Plastics Industry Databases (PID) $\ldots \ldots \ldots \ldots \ldots \ldots \ldots, 17$

3.2.1.1.13 Electric Power Research Institute (EPRI) Databases .. 17

3.2.1.2 PC-Based Materials Databases ....... 17

3.2.1.2.1 Materials Research Iaboratory (MRL) Database ........ 18

3.2.1.2.2 DATEX $\ldots \ldots \ldots \ldots \ldots \ldots \ldots, 18$

3.2.1.2.3 MetSel2 $\ldots \ldots \ldots \ldots \ldots \ldots \ldots, 19$

3.2.1.2.4 IBR $\ldots \ldots \ldots \ldots \ldots \ldots \ldots \ldots, 19$

3.2.1.3 Databases for Both Mainframes

and $\mathrm{PCs} \ldots \ldots \ldots \ldots \ldots \ldots \ldots \ldots \ldots, 20$

3.2.1.3.1 HIMIAC $\ldots \ldots \ldots \ldots \ldots \ldots \ldots, 20$

3.2.1.3.2 MatDB ................. 21

3.2.2 Hardcopy Databases (Handbooks) .............. 22

3.2.2.1 Concrete Technology Information

Analysis Center (CIIAC) $\ldots \ldots \ldots \ldots \ldots, 22$

3.2.2.2 American Concrete Institute (ACI) ..... 22

3.2.2.3 Institut für Bauforschung at Aachen ... 23

3.2.2.4 Kernforschungszentrum at Karlsruhe (KAK) $\ldots \ldots \ldots \ldots \ldots \ldots \ldots \ldots \ldots, 23$

3.2.2.5 Deutscher Beton-Verein (DBV) $\ldots \ldots \ldots . .23$

3.2.2.6 Japanese Databases $\ldots \ldots \ldots \ldots \ldots \ldots \ldots .23$

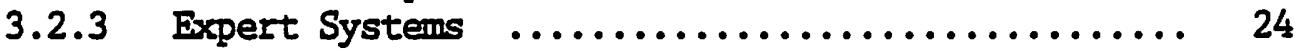

3.2.3.1 DURCON $\ldots \ldots \ldots \ldots \ldots \ldots \ldots \ldots \ldots \ldots \ldots, 24$

3.2.3.2 IKSMAT $\ldots \ldots \ldots \ldots \ldots \ldots \ldots \ldots \ldots \ldots \ldots .24$

3.2.3.3 Expert System on the "Repair of Concrete Structures" $\ldots \ldots \ldots \ldots \ldots \ldots .25$

3.2.3.4 CRACKS $\ldots \ldots \ldots \ldots \ldots \ldots \ldots \ldots \ldots \ldots, 25$

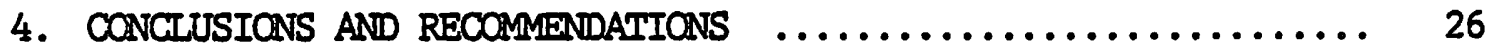

4.1 Concrete Materials Databases $\ldots . \ldots \ldots \ldots \ldots \ldots \ldots \ldots . . \ldots 26$

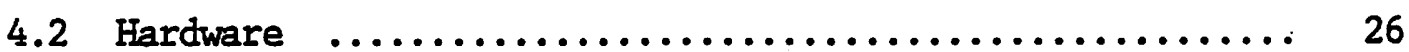


Page

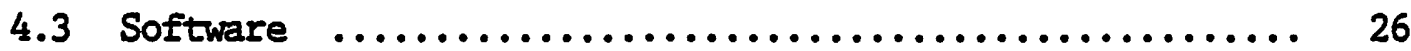

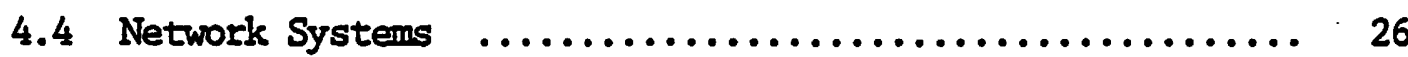

4.5 Future Plans $\ldots \ldots \ldots \ldots \ldots \ldots \ldots \ldots \ldots \ldots \ldots \ldots \ldots \ldots \ldots . \ldots \ldots \ldots$

4.5.1. Liaison Organizations and Activities ......... 27

4.5.1.1 ASTM Committee E49 ............... 27

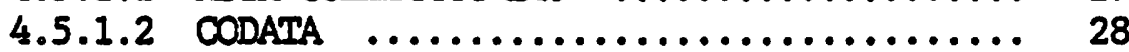

4.5.2 Choose Software and Hardware $\ldots \ldots \ldots \ldots \ldots \ldots . \ldots . \ldots 28$

4.5.3 Finalize Formats ........................ 29

4.5.4 Collect. Evaluate, and Distribute Data ....... 29

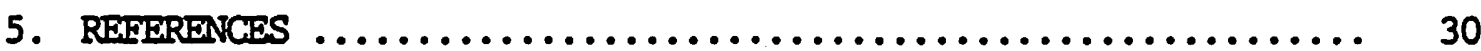

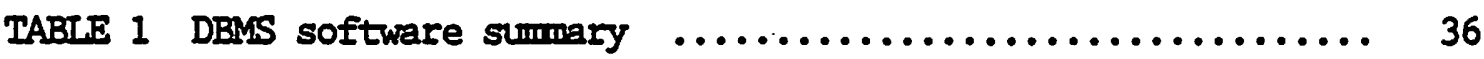

TABLE 2 Computerized databases $\ldots \ldots \ldots \ldots \ldots \ldots \ldots \ldots \ldots \ldots \ldots \ldots \ldots \ldots$

TABTE 3 Hardcopy databases (handbooks) $\ldots \ldots \ldots \ldots \ldots \ldots \ldots \ldots . \ldots . \ldots$

FIGURE 1 Data flow diagram - structural materials database

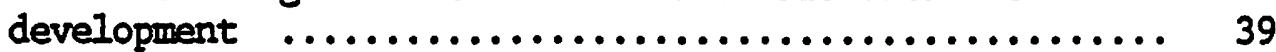


M. F. Marchbanks

Oak Ridge National Iaboratory

\section{ABSTRACT}

This review and assessment of materials property databases is part of the Structural Aging (SAG) Program in preparation for the development of a centralized collection of structural materials properties at the Oak Ridge National Iaboratory (ORNL). The objective of the Structural Aging Program is to provide the USINRC with structural safety issues and acceptance criteria for use in Nuclear Power Plant (NPP) contimed service evaluations. This review and assessment will form the basis for development of the Structural Materials Information Center (SMIC). The SMIC will be utilized to assist in the prediction of potential long-term deterioration of critical safety-related structures in NPPs, and to establish limits on hostile environmental exposure for these structures. The SMIC will be composed of an electronic database, the Structural Materials Database (SMDB), and a handbook, the Structural Materials Handbook (SMHB). Two concerns were addressed: (1) making the best choice of software on the basis of economics and ease of use, and (2) finding or developing data applicable to the needs of the SMIC. The initial focus centered on electronic and hardcopy databases containing concrete materials property data describing the effects of environments typical of Light Water Reactors (LWRs).

This study produced some references that report on the properties of concrete under nuclear power plant conditions. These references will provide some basic information for the SMIC on the properties of concrete exposed to LWR conditions. However, the information obtained generally supports the conclusion reached elsewhere, that the data on the aging of concrete materials are very limited. The search for applicable data will contimue, and will be supplemented by the appropriate tests, under the direction of the SAG Program. IBM PC computers and compatibles are recommended for the system hardware, and the ASM International materials database program $\mathrm{MatDB}$ is the recommended software. A brief description of recommended technical approaches for the SMIC is presented, including the contacts and options that should be maintained to promote the development of a professional and useful 
database system that will have wide acceptance among materials engineers.

\section{INTRODUCTION}

This review and assessment of materials property databases is being conducted as a part of the United States Nuclear Regulatory Commission (USNRC) Structural Aging (SAG) Program. The overall objective of the SAG Program is to provide the USINRC with structural safety issues and acceptance criteria, as well as their bases, for use in Nuclear Power Plant (NPP) contimed service evaluations.D.1* A vital component of this program is the development of a centralized collection of materials property data into a Structural Materials Information Center (SMIC) at the Oak Ridge National Iaboratory (ORN). The results of this review and assessment will form the basis for development of the SMIC. It will be utilized to assist in the prediction of potential long-term deterioration of critical safety-related structures in NPPs, and to establish limits on hostile environmental exposure for these structures. The SMIC will be composed of an electronic database, the Structural Materials Database (SMDB), and a handbook, the Structural Materials Handbook (SMHB). The SMDB and SMIB will be developed congruently, with the electronic database serving as the information source upon which the handbook is built. The SMDB will consider the needsD.12.D.23 of the typical user of materials properties databases, with a focus on the specific needs of USNRC license reviewers and Iicensees relative to contimed service assessments of muclear power plants.

The use of certain terms in a discussion of databases can have different meanings to different readers. so an explanation of the terms used in this report should be given at the outset:

1. A database source is considered to refer to the information contained in either a computer file or as hardcopy, such as a handbook.

2. A database file is the database source formatted and transferred to an electronic file for use in a database.

3. A "Database Management System" is the computer software that accesses and manages the database file.

"References are characterized as either document or source references. The document references are preceeded by $a$ D and the source references by a $\mathrm{S}$. 
4. A database refers generically to the combined system of database file and database management system. whether the Structural Materials Database or some other database. 


\section{SUMMARY}

\subsection{Rurpose}

Several different approaches are possible in the provision of a database for concrete materials properties." Two concerns are apparent: (1) making the best choice of software on the basis of economics and ease of use and (2) finding or developing data applicable to the needs of the Structural Materials Information Center. The purpose of this study is to identify the software and, if possible, existing database sources (electronic or hardcopy) that will best address these concerns.

\subsection{Scope}

The search for existing materials property databases emphasized those developed for cementitious material systems, whether currently in electronic or hardcopy form. Of particular interest was the location of databases that contained concrete materials property data describing the effects of enviromments typical of Iight Water Reactors (IWRs).

The evaluation of database management systems (DRMSs) emphasized a study of the potential for application in the Structural Materials Information Center (SMIC), rather than a full-blown benchmark evaluation of DBMSs such as has been performed elsewhere.D.2 It examined the hardware and software options, and surveyed the field for available DBMSs. An important requirement for the DBMS chosen for use by the SMIC. whether purely a DMBS or contained in an existing database, is that it mist have the facility for easily adding information collected or generated by the SAG Program.

Bibliographic databases, while numerous and potentially useful for the location of numerical information, were not revlewed, except in certain specific cases. The emphasis was rather on databases that might contain the mumerical information of interest to the SAG program. or that might use software that could be utilized in the Structural Materials Database.

\subsubsection{Database Management System}

2.2.1.1 Database Management System Hardware Types. The choice of hardware for a database system intended for use by a large number of users distributed over several user sites has to be a compromise of needs. This comes about because of the diverse types and brands of systems in use. For this study, the types of hardware available were

"Although the database is being established for all structural materials in nuclear power plants that may be subjected to environmental stressors or aging factors, the emphasis of this report is on concrete material systems. 
broken down into three main systems: (1) mainframes. (2) Apple computers, and (3) personal computers. Other systems, such as "work stations," could be considered, but the three chosen were considered to best represent the equipment currently in use by most potential users of the Structural Materials Database.

There are a great many mainframe systems currently offering database operations. Mainframes offer the advantage of speed, versatility and large capacity. The disadvantages include the expense of line charges and the instability often encountered with large computer systems. An important consideration with respect to the Structural Materials Database is the software packages offered on mainframes.

Apple computers and IBM or IBM compatible personal computers are both common in the engineering workplace. An ideal situation would exist if there were complete compatibility between the two. This is not the case, but efforts toward compatibility are being made. There are both hardware and software approachesD.24 that enable Apple computers to run DOS based applications. Experience in the use of these conversion tools at ORNL has been limited. Some report that the conversion software does enable Personal Computer (PC) programs to be run on Apple computers, but the execution time is extremely slow. Others have found that the speed is acceptable, about that of the IBM PC XI. Apple computers should work as well as IBM or IBM compatible personal computers when functioning as a terminal emulator for connection to mainframes.

The main emphasis of this review and assessment was software for equipment compatible with the IBM Personal Computer family (PCs), the hardware of choice for the USIRC and many of the potential users of the Structural Materials Database.

2.2.1.2 Database Management System Software Classification. Software was divided into three categories: (1) Standard. or existing software that can be used essentially as-is, (2) Customized Standard. which is existing software that can be easily modified to fit specific needs, and (3) Customized, which pertains to software developed "from scratch." using a database management system (either conmercial or developed in-house), a high level language to drive the system, and perhaps a windows program to enhance usability.

The most cost effective and convenient approach to development of the Structural Materials Database would be to locate an existing database that would meet the specific needs of the SAG Program. This survey was conducted with the location of such a "standard" software as a primary goal.

The location of a standard database was most desired. However, the probability of finding one that would meet specific needs was not 
considered to be large. Therefore, the second preference was to locate a database, preferably one designed for concrete materials, which could be easily modified to make a customized standard database.

The third and least desirable approach was the development of a database using a high level language such as C, BASIC, or FORTRAN. either alone or in conjunction with a commercial database management system program, and applications programs for windows and spreadsheets. This approach would be the most time consuming and costly, but would also provide a custom built system tailored to the SAG Program specifications. 


\section{REVIEW RESULTS AND ASSESSMENT}

The results of the review and assessment of several database management systems and database systems follow. In most cases, the descriptions and conclusions are based solely on the information provided by vendor product descriptions, and reviews in technical journals and discussions with other users. Actual experience with databases and database management systems was limited by resource constraints to only a few products. The paragraphs discussing each system are prefaced by the headings "Description $-"$, and "Considerations for Structural Materials Information Center (SMIC) Use - ." Indicating the nature of the remarks.

\subsection{Database Management_System Software Reviews}

Many database management systems (DBMSs) have been developed by both commercial, private, and government concerns. The commercial offerings alone number more than 100 different systems.D.19 It is far beyond the scope of the Structural Materials Information Center activity to make an exhaustive review of this vast area. so this report is limited to a relatively few DBMSs known to be used in the field of materials properties documentation. The DBMSs of today are ustally described as either a third-generation language, which is characterized by a procedural command language, or fourth-generation language, in which the program implements the structured query language and writes the procedures for accomplishing requested tasks.

The findings of the database management system (DBMS) software review are summarized in Table 1 . The three columns headed "Type of Software" refer to the categories given in the above section. "DBMS Software Classification." The cost figures given in the table and below should be considered guidelines only, and could vary significantly depending on the options selected. In addition, the costs given do not attempt to include development activities, which would depend on the amount of programming necessary, and may involve other costs such as licensing fees for windowing or other applications software.

\subsubsection{Mainframe Database Management Systems}

Mainframe applications for the Structural Materials Information Center were considered because of their power and versatility, and because of their present or potential availability on ORNL computer systems.

3.1.1.1 INGRES. Description - INGRES is a relational database management system produced by Relational Technology. Inc.. in Alameda, California. It includes many individual subsystems to help users to enter, query, update, and analyze data. Output from inquiries is provided as reports, graphs, forms, or unformatted display of data. Its 
assets include: full implementation of structured query language, inclusion of host language interface for $C$ language, easy browsing, and complete, accessible documentation. D.20

Considerations for Structural Materials Information Center (SMIC) Use - INGRES is a good candidate for use in the SMIC. This is especially true if the Structural Materials Database is installed in the WNN system (discussed in Section 3.2.1.1.1). since INGRES is already resident there.

Cost: Since INGRES is already on the WIN system, no purchase would be necessary. However, considerable development costs would be required to prepare a system formatted for SMIC use. This would be the case for all mainframe database management systems.

3.1.1.2 SPIRES. Description - SPIRESD.18 is a general purpose database management system developed at Stanford University and supported by a consortium of users. It runs on more than 30 installations. Major contributions to the system design were made by Lawrence Berkeley Iaboratories and Sci-Tech Knowledge Systems. Inc. It has capabilities for mmeric and textual data. can handle large mubers of simultaneous users. is flexible and expandable, and has a history of support for innovative applications. It is considered a fourth-generation language database management system with full data management capabilities including schema definition and control, report generation, full-screen form design, online documentation, etc. It does not provide graphical output or computational capabilities.

Considerations for Structural Materials Information Center (SMIC) Use - SPIRES has been used in other materials properties databases ${ }^{D} .18$ because of its many features, but would have to be used in conjunction with other software in order to provide graphics. In addition, it has been found to lack portability, 5.5 an important feature in system networking. which may be a consideration in the development of a system for the SMIC. Other databases builders have opted for a commercial system in order to circumvent this problem. It would be advisable for the SMIC to follow the same route, even if the PC approach is initially selected, in order to keep the option for networking open.

Cost: There is a one-time (organizational) 1icense fee of $\$ 1,000$ to join the consortium, and an anmual fee of $\$ 7.500$ to remain on the consortium.

3.1.1.3 MESSENGER. MESSENGERD.18 is a highly efficient bibliographic database management system designed to handle extremely large numbers of records. It is a proprietary software developed by the American Chemical Society for use on the STM International system, and is not available for purchase or leasing. 
3.1.1.4 ORACT.E. Description - ORACLE is a fourth-generation language relational database management system from the Oracle Corporation that is operable on a wide variety of mainframes, minicomputers and PCs. The term "high end" refersD.20 to the corporate mainframe/minicomputer roots of the program. ORACLE has the advantage of being completely compatible with IBM's mainframe structured query language/DS and DB2 systems. Structured query language statements are processed and executed through a shell. The ORACLE data dictionary maintains the entire database and offers information on every aspect of the database: tables, users, indexes, data spaces, and access privileges.

Considerations for Structural Materials Information Center (SMIC) Use - Several major database builders, including the National Aeronautics and Space Administration, the MPD Network, and the National Institute of Standards and Technology (NIST), formerly the National Bureau of Standards (NBS), have selected ORACIE. If the route of developing a Customized database on a mainframe network is chosen by the Sag Program, this would be a consideration.

Cost: The lease charge for the software is $\$ 150,000$ per year.

\subsubsection{RC Database Management Systems}

3.1.2.1 ORACTE. Description - As mentioned above, ORACTE is available in both mainframe and PC versions. Like the mainframe version. the PC version has the advantage of being completely compatible with IBM's mainframe structured query language/DS and DB2 systems. It is "robust and full-featured, includes full structured query language implementation ... (contains a) spreadsheet, report generator. IAN support system, C language environment. (and is) very powerful." $\mathrm{D} .20$

Considerations for Structural Materials Information Center (SMIC) Use - It should be noted that all high end database management system products, by virtue of their mainframe roots, retain a "mainframe mindset." This means that importing data from other PC programs may involve lengthy preparations such as data format alterations and program writing. Knowledge of the great power afforded by ORACLE should be tempered with the fact that the program has been rated "needlessly difficult to learn and use."D.20 In addition, the documentation is considered hard to read and use, and there are expensive hardware requirements. Some of these drawbacks would be overcome for the user by the incorporation of a SMIC-supplied, user friendly driver program. whether the final application is PC. mainframe, or both.

Cost: \$1,295 for the basic system, software and hardware requirements would increase the cost for some users (PS/2, AT, Compaq 386 or compatibles; 640K RAM plus 896K extended memory, hard disk with $7.5 \mathrm{Mb}$ free to hold the program.) 
3.1.2.2 INGRES. Description - Essentially the same characteristics as for the mainframe version. described above. ${ }^{D .20}$

Considerations for Structural Materials Information Center (SMIC) Use - INGRES is a fourth-generation language that crosses the mainframe/PC boundary in a smooth fashion that offers easy accessibility to powerful database creation. query and reporting. If the structural materials database were to be installed on the WIN system using the mainframe version of INGRES, the use of INGRES at the PC level would assure ease of file downloading.

Cost: $\$ 950$ for the basic system, $\$ 500$ for the fourth-generation language package, and $\$ 400$ for the host language (C) interface.

3.1.2.3 dBase. Description - Iike most of the other PC database management systems (DBMSs). dBase has experienced several updates to keep competitive in the market. It is by far the best selling DBMS, but until recently its features have lagged behind those of other brands. .20 However, with the recent release of dBase IV, dBase has moved into the fourth-generation language category, while retaining compatibility with files created on earlier versions.

Considerations for Structural Materials Information Center (SMIC) Use - Most database management systems are moving closer to the needs and desires of the user. dBase IV is an example of this, and because of the large number of engineers already familiar with the program, that would be an important plus for users of the Structural Materials Database. The "Developer's Edition" of dBase IV allows developers to build royalty-free compiled dBase applications for distribution to users, and an add-on graphics program is available.

Cost: $\$ 795$ for the basic dBase IV system, $\$ 1,200$ for the Developers Edition of dBase IV. $\$ 375$ for the add-on graph package (Chart Master Version 6.21).

3.1.2.4 Rbase. Description - Rbase for DOS. Version 2.0 is described as the "closest to being all things to all people."D.20 It provides features needed by developers of extensive applications, but also makes interactive use easy for the user.

Considerations for Structural Materials Information Center (SMIC) Use - Rbase was the database management system of choice for Phase I of DATAX, which is described below. It provides good graphics support through an add-on program, and complied applications programs can be developed for distribution to users.

Cost: \$795 for the basic system, \$250 for Rbase for DOS Run Time, an application development package (1imited to 5 copies), \$895 for Rbase Complier, an application development package with unlimited copying. 
\$595 for Program Interface, to interface Rbase with any of several highlevel languages, \$295 for DbGraphics, a graphics package.

3.1.2.5 MetSe12 and MatDB. See the discussions below under "PCBased Materials Databases."

\subsection{Database_Reviews}

In the course of this review, requests for information were sent to a number of potential information sources worldwide. It was not always possible to determine from the responses whether their systems were housed in a mainframe or PC. or were hardcopy systems only. In general, for the classification used below, if no mention of computer application was made, a hardcopy database was assumed. If computers were indicated but not specified as mainframe or PC, a mainframe system was assumed.

\subsubsection{Computertized DBs}

3.2.1.1 Mainframe materials databases. A brief review of mainframe DB systems was made for two reasons: (1) they offer features that may be helpful in the development of a structural materials database, whether mainframe or PC and (2) they offer certain advantages that may indicate adoption of a mainframe system over a PC system.

There are many commercial databases which provide valuable assistance to the materials engineering community in the form of bibliographies and overviews of trade names, suppliers, services. standards and properties. Most of these "general purpose" databases do not provide the database management system format or materials information necessary for the storing and retrieval of numerical data for materials research and development applications. Such databases include MATUS, D.3 TIS,D.9 STN International,D.16 METADEX,D.15 CAN/SND,D.17 SAE.D.21 and IHS.D.22 Although these databases may provide valuable references for the location of needed materials information, they provide little guidance in the development of a mumerical database.

In addition to the general purpose databases, there are in existence databases which more readily lend themselves to materials properties storage, analysis, and retrieval. The few numerical databases for materials (e.g., METALS DATAFII. $E^{\mathrm{D}} .15$ and MetSel2 ${ }^{\mathrm{D} .26}$ ) are generally limited in content to metals and alloys. It is possible. however. that information on concrete and cementitious materials, as well as other structural materials, may be added to and effectively handled by some of these databases. The specific databases found to be of potential interest to the Structural Materials Information Center are sumarized in Table 2. A detailed analysis follows. 


\subsection{Waste Information Network (WIN)}

Description - WIN is a national comminications network developed for the Department of Energy under the Hazardous Waste Remedial Actions Program (HAZWRAP). It functions as an information tool that provides databases, electronic mail, bulletin boards, and file transfer, and also has the factlity for some data analysis. WIN is not a database management system or database per se, but is a network server. The database would have to be developed.

Considerations for Structural Materials Information Center (SMIC) Use - Although many of the programs in WIN are specially designed for HAZWRAP, it has many operational capabilities of generic technical use. This has enabled WIN to make a recent expansion in scope to include many other engineering applications. A database specific to the SMIC needs could be provided for the WIN system, and would have access to the power of the WIN system. If the decision is made to place the Structural Materials Database on a mainframe with dial-up access, the WIN system would be a good candidate.

Cost: $\$ 1,000$ per year for each user station.

\subsection{Safety Analysis Computerized_Reactor Data (SACRD)}

Description - The SACRDD.13 is a currently inactive, computerized database designed to provide a central collection of evaluated data for use in fast reactor safety computer codes. Its scope encompasses information related to liquid-metal fast breeder reactors, especially at extreme conditions where experimental data are sparse. The SACRD format provides data evaluation abstracts, tabular data. graphical representations and equations, all accessible through remote terminals. JOSHIA,D.14 a database management system developed at Savannah River Laboratories for the DOE, was used to maintain the SACRD on a mainframe computer located at the Oak Ridge National Laboratory.

Considerations for Structural Materials Information Center (SMIC) Use - The reactivation and maintenance of the SACRD system for the Structural Materials Database (SMDB) would require a support level of two to three Full Time Equivalents per year. In addition, the current JOSHUA version would have to be replaced because the compiler on which it is based is being discontinued at the end of FY 1989. A new version is available, but distribution is limited by the Applied Technology label. which restricts access to U. S. citizens. The cognizant engineerS.1 for the former SACRD program recommended that a commercial database management system that is available for both mainframes and PCs would be a better choice for the SMDB.

There was an appreciable amount of concrete materials properties scheduled for inclusion in the SACRD database when the program was 
terminated in 1982. However, much of the information is specified as Applied Technology, and special arrangements will have to be made with DOE to use the information in an "Open" database such as the Structural Materials Information Center.

\subsection{Nationa1 Materials Property Data Network (MPD Network)}

Description - The MPD Network ${ }^{D} 7$ (MPD) was incorporated in 1984 to function as a not-for-profit organization providing U.S. engineers and scientists with materials properties and performance data. It is an ongoing effort promoting the development and linking of worldwide high quality databases. It incorporates developments from other systems such as TIS.D.9 and when developed will include the following features: (1) on-line access to multiple sources of information. (2) distributed sources, (3) evaluated data, and (4) a Metadata" system (a nomenclature translator for accessing materials and properties in various systems). In addition, the MPD Network Newsiletter is a valuable source of information on other materials databases being developed worldwide, whether directly connected with the MPD Network or not. Funding for the activity comes from a variety of public and private sponsors.

An on-Iine pilot MPD Network was developed at Stanford University to $\mathrm{rm}$ on an IBM 3084 under SIS at Stanford's Information Technology Services. The pilot system is based on the Materials Information for Science and Technology (MIST)D.10 networking technology developed jointly by the National Institute of Standards and Technology and the Departmend of Energy. The database management system used for the prototype system is SPIRES.D.18 a general purpose database management system developed and supported by Stanford University. MESSENGER D.18 is being used in the production system now being built. Because both SPIRES and MESSENGER are relatively difficult to transfer, the MPD Network has chosen ORACTE, a commercial database management system, for future development work.

Considerations for Structural Materials Information Center (SMIC) Use - The MPD Network is still considered an experimental project, and as such does not offer a system of immediate use to the SAG Program. However, extensive development has been done on their existing pilot network, and this activity should be monitored for possible future application. Sponsors for the MPD Network are solicited from government and industry. They direct input of ideas into the project, have immediate access to the pilot network, receive cost benefits when the system reaches production, and receive a regular flow of information on worldwide materials data activities.

Cost: The cost to each sponsor is nominally $\$ 10,000$ per year 


\subsection{Radiation Shielding Infonation Center (RSIC)}

Description - The RSIC at ORNL is a computer bibliographic library concerned more with nuclear properties than physical or mechanical properties. It contains some references on concrete, and searches can be made by concrete type. Printouts can be made with or without abstracts. On-line services are not provided.

Considerations for Structural Materials Information Center (SMIC) Use - The database management system used by RSIC is not applicable to the needs of the Structural Materials Database. However, some of the references in the RSIC may contain concrete properties, and a printout of the RSIC files would be useful in the search for information for input to the SMIC.

\subsection{Construction Engineering Research Laboratory (CERI)}

Description - CERL is developing a database for the evaluation of cracks in concrete.S.3 The CERL database will not contain mechanical properties, but rather a set of rules for evaluating cracking and spalling. The database generates an index muber that gives a measure of the remaining life of the concrete structure in question. and produces suggestions on repair techniques. The application is for gravity structures only, not reinforced concrete.

Considerations for Structural Materials Information Center (SMIC) Use - Although the CarL database does not contain mechanical properties for input to the SMIC, the rationale used in rule development could be of use in the development of methodologies for other areas of the SAG Program.

Cost: Not determined.

\subsection{Metals and Ceramic Information Center (MCIC)}

Description - The MCIC is an information analysis center operated by Battelle's Columbus Laboratories for the DOD. It is located on a DOD-owned UNIVAC cluster and runs on machine language, rather than a database management system software. The MCIC is part of the DOD Information Analysis Center complex. managed and funded by the Defense Logistics Agency and the Defense Technical Information Center. On-line access is provided through the Defense Research. Development. Test, and Evaluation On-Iine System. The system provides strictly bibliographic information, not mumerical data or graphics output.

Considerations for Structural Materials Information Center (SMIC) Use - The MCIC software is a highly specialized system, and does not offer any software useful to the SMIC. Although it does not provide numerical information, it is possible that some of the 12 documents containing concrete information may have some useful data. 
Cost: Not applicable.

\subsection{Mechanical Properties Data Center (MPDC)}

Description - Iike the MCIC, the MPDC is an information analysis center operated by Battelle's Columbus Laboratories for the DOD. It was formerly a separate on-line mmeric database, but has been absorbed into the MCIC, and now provides only bibliographic information. However, there are notations in the MPDC records to indicate the references that contain mmerical information. The materials covered are primarily those used in aerospace and defense projects, including metals, ceramics and composites.

Considerations for Structural Materials Information Center (SMIC) Use - Since the MPDC has been absorbed into the MCIC, the conclusions on its usefulness for SMIC applications are the same.

Cost: Not applicable.

\subsection{U.S. Coast Guard Database (MARTUE)}

Description - MARIUF is a new database being built for the U. S. Coast Guard and the Ship Structures Committee on the toughness of steels for marine applications. It will be incorporated as a Materials Property Data Network database. Its database management system format provides searchable fields for test sample compositions, fabrication details, weld procedure documentation, filler alloy composition, postweld treatments, test conditions and test results.

Considerations for Structural Materials Information Center (SMIC) Use - Although the MARTUF database content would probably have no direct application in the SMIC, it contains a significant database management system format feature with possible application. It will be unique among materials databases in the completeness of the characterization of test samples. Among the most difficult and frustrating aspects of using data from the literature is the lack of documentation of the test material. with the result that source-to-source comparisons are difficult. This source-to-source comparison of test information will be of primary importance in the development of SAG Program methodologies. Thus the MARTUF database may provide format characteristics of use to the SMIC.

Cost: Not yet determined.

\subsection{European Materials Information Services_Network (EMISN)}

Description - The EMISND.17 is an effort by the Commission of European Commmities to integrate existing materials information services in Europe. A pilot network has been organized, containing 
eleven databanks in five different countries. The subjects covered include chemical interactions, processing descriptions, and mechanical and physical properties of materials.

Considerations for Structural Materials Information Center (SMIC) Use - Concrete materials are not presently included in the European database, but they may be added in the future. For this reason. developments in this activity should be monitored. Some of the databases covered may use software that could be of use to the SMIC. However. it would probably be more productive to pursue domestic software before expending the effort to look into foreign sources.

Cost: Not applicable.

\subsection{Institut fïr Massivbau und Baustoffechnologie}

Description - The Institut fuir Massivbau und Baustofftechnologie (Universität Karlsruhe) S.6 has developed a database on the creep and shrinkage of concrete. This data bank is part of a joint database of the American Concrete Institute (ACI) and the Comite Euro-International du Béton (CEBB). now under preparation. This database will be used to optimize creep and shrinkage prediction models.

Considerations for Structural Materials Information Center (SMIC) Use - Creep and shrinkage are important properties for lifetime assessments of concrete. This contact will be pursued for possible input to the SMIC. (The ACI contact is Dr. L. Panula. TAMS. The Tams Building, 655 Third Avenue, New York, N. Y. 10017.)

Cost: Not determined.

\subsection{Iniversity of Tokyo}

Description - Dr. Shuichi IwataS.7 of the The University of Tokyo knows of many small database projects in Japan which contain small amounts of information on concrete materials, but there is no database specifically devoted to concrete. A large amount of work would be needed to prepare such a database from the large number of general databases.

Considerations for Structural Materials Information Center (SMIC) Use - Dr. Iwata is also interested in the extension of operating life of power plants, and is engaged in the organization of an activity on the subject in Japan. He has promised to search further for Japanese data that will be of use to the SMIC.

Cost: Not applicable. 


\subsection{Plastias Industry Databases (PID)}

Description - Plastic engineering materials are proliferating at a phenomenal rate, and so are the databases being constructed to keep track of them.D.43 A few were chosen to be mentioned here as a representation of their capabilities and potential application to the Structural Materials Information Center.

General Electric has butlt a module for the Engineering Design Database that supplies graphical and textual representations of physical and mechanical properties. The software is capable of interpolating or extracting the data, and comparison displays can be obtained. DuPont has an on-line database called Polyfacts which is similar in operation and features to the General Electric database. Plaspec is an on-line database operated by Plastics Technology magazine. Plastivision provides physical properties and features of plastics as a Compuserve/BorgWarner database.

Considerations for Structural Materials Information Center (SMIC) Use - These databases may provide some assistance to building the Structural Materials Database, and will be considered a backup source of potential information.

Cost: Not determined.

\subsection{Electric Power Research Institute (EPRI) Databases}

The EPRID. 44 has organized several databases which contain materials properties of interest to the malear power industry. The databases include: EDEAC - EPRI Database for Environmentally-Assisted Cracking; MATSURV - Materials Surveillance, Nuclear Reactor Pressure Vessel Steel; Irradiated Nuclear Pressure Vessel Steel: Metal Properties Council/ Pressure Vessel Reactor Committee Fracture Toughness: Atomic Industrial Forum/Metal Properties Council Structural Steel; and Atomic Industrial Form/Metal Properties Council Bolting. The applications include materials screening and selection, materials development and improvement. modeling of materials behavior. failure analysis and remedy development. design criteria establishment, and prediction of component life.

Considerations for Structural Materials Information Center (SMIC) Use - EPRI has learned valuable lessons in developing these databases. Although the databases they have developed do not relate directly to concrete materials, the experience gained may be of value to the development of the SMIC.

Cost: Not determined.

3.2.1.2 PC-based materials databases. The last ten years or so have seen a few efforts at developing databases specifically designed 
for material properties representation on PCs. Some of these have been research ventures sponsored by professional organizations, and a few have reached the commercial stage.

\subsection{Materials Research Laboratory (MRT) Database}

Description - The MRLS.4 at Penn State University has developed a database format for the Strategic Highway Research Program (SHRP). The MRL has operated a database since 1979. Initially on a mainframe, and is now in the process of transferring the database to a PC. using dBase III+ software.

Considerations for Structural Materlals Information Center (SMIC) Use - The MRL database contains information on cement paste, grouts, and mortars, with only a small amount of information on concrete. They have found that not much well characterized information on concrete is available. Although their data are sparse, the SMIC should maintain a liaison with MRL to promote mutual benefits in database design and data gathering.

Cost: Not determined.

\subsection{DATAX}

Description - DATAXD.11 began in 1978 as a Natinal Bureau of Standards software research and development project designed to demonstrate the feasibility of database building, networking and on-line evaluation of engineering data. The goal is to integrate graphics. analysis, word-processing. file manipulation, database management and network access, and to provide sanctioned guidelines to accomplish these activities. The ASME Committee on Research Needs became Involved in the project in 1981. Phase I of the project, which featured a tutorial to train engineers in database building, was completed in 1986. The emphasis was on the development of databases using a commonly available tool. the IBM XI or compatible, and a relatively powerful, economical commercial database. The intent was to reduce reliance on "handbook" database systems that contain a large amount of information that is irrelevant to specific needs. while at the same time fostering a standard approach to database construction that will encourage comminication and data sharing among engineers. Two types of data sets were used to develop examples in Phase I: (1) fatigue of metallic alloys, and (2) creep of metailic alloys.

Upon completion of Phase I. the DATAX project was presented as a candidate for ASME-sponsored software research and development in collaboration with government and industry. If implemented. Phase II will propose an integrated software system for PCs to assist in the cooperative on-line analysis, retrieval, and evaluation of materials property data. 
Considerations for Structural Materials Information Center (SMIC) Use - The DATAX project has made a valuable contribution in the promotion of the use of databases by engineers. It has provided valuable guidelines and examples to the engineer in developing his or her own database, and has suggested a system of files and procedures for facilitating database sharing between engineers. These contributions are expected to give significant help, and will be considered in the design of the Structural Materials Database.

\subsection{MetSel2}

Description - MetSe12.D.26 a PC materials database software package from ASM International designed for the representation of metals and alloys information, is a menu-driven, interactive program with windowing facilities. The selection process allows defining and redefining of the selection criteria for accepting or rejecting materials. The searches can combine materials properties, chemical compositions, material groups, classes and rankings according to material reactions to certain treatments and conditions. manufacturer. country of origin, designations, specifications, or user-supplied identifying keywords. The database can be edited to add data, comments, specifications. proprietary property information, and other information. Graphics can be added to the database through the use of a companion program. EnPlot. which has the facility for importing data files, curve fitting, scale conversion, and other data analysis operations.

Considerations for Structural Materials Information Center (SMIC) Use - ORNL members of the SAG Program have obtained a copy of MetSe12 and the companion plot generation program EnPlot, and have evaluated them for use in the SMIC. MetSel2 is produced by an organization devoted to providing information to the materials professional. As such, it is a "handbook" program. designed to provide specific information on metals and alloys in a set format. rather than to perform as a database management system tool for input developed and formatted by the user. Input of user information can be done, but only in the MetSel2 format. These limitations are being overcome, however, with a new version of MetSel2. Details of the new version are given below in the discussion of MatDB. Cost: \$550 for MetSe12, \$390 for EnPlot.

\subsection{IBR}

Description - IBRS.10 is a German activity that has developed a PC database and software for quality control and guidance to concrete mamufacturers. Their system includes a materials properties database, manufacturer and price database, statistical processing of material properties, test data, and computation routines to support concrete mixing and production. 
Considerations for Structural Materials Information Center (SMIC) Use - The materials properties and test data databases may contain information valuable to the SMIC. This information source will be contacted again for possible input.

Cost: Not determined.

3.2.1.3 Databases for both mainframes and PCs. While the capability for fille transfer between mainframes and PCs and between different software packages is constantly being improved, there are still difficulties involved. Unique system protocols for such enhancements as superscripts, underlining, outlining, table construction and graphics are still not governed by a unifying standard. If the Structural Materials Database is placed on a mainframe. it would be advantageous to select a database management system (DBMS) that offers both mainframe and PC versions, so that users would have the option of obtaining software that would optimize comminications and downloading to their PCs. There are some DBMSs that are offered on both systems, such as ORACLE and INGRES, discussed above. Two activities found, which offer databases, not just DBMSs, on both mainframe and PC systems are discussed in the following two subsections.

\subsection{ETMTAC}

Description - The High Temperature Materials - Mechanical. Electronic and Thermophysical Properties Information Analysis Center ${ }^{D .42}$ (FIMIAC) is a computerized numerical data bank with on-line access, operated by the Center for Information and Numerical Data Analysis and Synthesis (CINDAS). The HIMIAC is a pilot experiment sponsored by the Defense Technical Information Center and is reserved for Department of Defense use only. CINDAS operates an information collection program on the properties of materials for science, engineering, and technology on a world-wide scale. Their activities include the compilation. evaluation and dissemination of technical data using exhaustive analysis techniques. Distribution is accomplished through publications, inquiry services, the HIMIAC, and an in-house Engineering Materials Properties Database.

The HIMIAC uses the UNIX operating system on a Sun-4 Computer with $32 \mathrm{Mb}$ of memory and operates using a database management system which was developed inhouse. The database management system provides graphics and tabular forms of output, and gives "instant response." Two databases are now on line, with two more in the development process. .14

The HIMIAC contains about 12.000 sets of data on the thermophysical, thermoradiative, optical, electronic, and mechanical properties of about 555 aerospace materials. Not all of the data on the system are ranked according to quality, but an estimated accuracy for the data is provided. A "free format" type of input is used, rather 
than printed input sheets with predefined columns and rows. This is because it was found that often there would be available only a few words or lines of material and data descriptions per page.

CINDAS is developing a PC database management system for the Semiconductor Research Center. It will be finished before June 1989. according to the contract. The applications program is provided as an integral part of the database. The same thing could be done for the Structural Materials Information Center.

CINDAS has a collection of documents on the thermophysical properties of concrete up to 1983, the year the funding for that project was dropped. Also available is a "huge" up-to-date collection of data on the properties of rocks and minerals.

Considerations for Structural Materials Information Center (SMIC) Use - Both the CINDAS mainframe and PC database management system are of potential use to the SMIC. An in-depth evaluation for compatibility with concrete materials and other SMIC requirements would be required. however, before either system could be recommended. CINDAS appears to have a good start on a collection of documents that contain concrete data, and would be a good source of quality information. Such information bears a price, however, and use of CINDAS services would involve a detailed listing of data requirements and the letting of a contract to perform the work.

Cost: Not determined, would have to be negotiated.

\subsection{MatDB}

Description - MatDB is to be the next version of MetSe12. Its new name reflects a broader scope as a database for all materials. not just metals and alloys. It is designed by materials engineers for use by materials engineers. Enhancements include the ability to generate more detailed reports, the comparison of property values at specified temperatures for specified materials conditions, and the editing of screen prompts. A version of MatDB is also being prepared that will run on the Digital Equipment Corporation's VAX family of computers. Development of both MatDB and the VAX version is being shared in a consortium of companies that supply their needs and requirements for consideration by the database builders.

Considerations for Structural Materials Information Center ( SMIC) Use - MatDB is considered to be a strong contender in the search for a database management system for the structural materials database. SAG Program members at ORNL have acquired the "beta-test" version of MatDB, and as members of the development consortium. have performed an evaluation and offered suggestions to the developers that emphasize the needs of engineers involved in materials R\&D programs. These suggestions have 
been well received, and the new version shows promise of being a powerful and flexible tool for the R\&D materials engineer.

Advantages to the use of MatDB in the SMIC system include: (1) It is a commercial system. thus development and maintenance costs are spread over a large muber of users. (2) its design is being strongly influenced by a wide representation from the materials field (concrete included). thus promising to be a powerful tool, as well as an exhaustive information source for materials engineers involved in either R\&D or applications, and (3) it is scheduled for operation on both the PC and mainframe, thus providing the capability of adding powerful networking capabilities that would be immediately compatible with personal desktop computers.

Cost: The cost of the PC version has not yet been released by ASM International. but is expected to be approximately the same as that for MetSel2 (about $\$ 600$ ). The one-time cost for the VAX version could vary from $\$ 20,000$ to $\$ 50,000$, depending on the amount of vendor-supplied materials information desired.

3.2.2 Hardcopy Databases (Handbooks). There are many known collectors of materials properties that distribute their information via papers, handbooks, periodicals, and other hardcopy forms. They were contacted for possible input to the Structural Materials Information Center. The results of these inquiries are summarized in Table 3.

3.2.2.1 Concrete Technology Information Analysis Center (CITAC). Description - The CIIACS.2 is operated for the Department of Defense by the U.S. Army Engineer Waterways Experiment Station. It is not a computer database, but contains a hardcopy library record of databases maintained by other organizations. References and abstracts are thus available in printed form.

Considerations for Structural Materials Information Center (SMIC) Use - While the CIIAC does not have a database that could be examined for SMIC application, the information it contains should be used to search for concrete properties information to be placed into the SMIC.

3.2.2.2 American Concrete Institute (ACI). Description - ACI is a professional organization specializing in cement and concrete materials. At one time, there was in existence an ACI projectS.2 to develop a database of computerized concrete information. However, the project was never completed.

Considerations for Structural Materials Information Center (SMIC) Use - The ACI is the largest concrete organization in the world. Contacts with the ACI should provide a wealth of information. In addition, assistance on the design of a database may be available from this organization. 
3.2.2.3 Institut für Bauforschung at Aachen (IBAC). Description This institute S.8 began a hardcopy collection of building materials in about 1978. but the effort was short-lived.

Considerations for Structural Materials Information Center (SMIC) Use - All comments received from the Institute were in the German language, and no data are currently available.

3.2.2.4 Kenforschungszentrum Karlsnuhe (KfR). Description - One of the functions of this nuclear research center, S.9 which is under contract to the Federal Ministry for Research and Technology, is organizing bilateral R\&D projects with research institutes of other countries. One of these projects (out of a few hundred) deals with concrete.

Considerations for Structural Materials Information Center (SMIC) Use - This contact should be followed up to see if there are any data useful to the SMIC. The German contact for the concrete project is Prof. Springenschmidt.. TU Miinchen.

3.2.2.5 Deutscher Beton-Verein (DBV). Description - This German contacts.11 supplied two referencesD.28.D.29 for the high temperature mechanical properties of concrete. In addition, two concrete experts S.6.S.8 were recommended for contacts on databases, and one contact (See under "Expert Systems") was supplied for an expert system on concrete structures.

Considerations for Structural Materials Information Center (SMIC) Use - These references and contacts will be pursued, or else have already been obtained and reported in this review.

3.2.2.6 Japanese Databases. Description - Eight concrete materials experts and twelve structural design experts located in Japan have been identified as possible sources of information on concrete properties under muclear power plant operating conditions.S.12 In addition, program personnel have obtained six reports ${ }^{D} \cdot 30-D .35$ on the properties of concrete $^{\text {S.12 }}$ and six reports D.36-D.41 on the elevated temperature properties of concrete ${ }^{S .13}$ from Japan.

Considerations for Structural Materials Information Center (SMIC) Use - Most of the contacts in Japan are professors or research engineers for large construction companies involved in high-temperature structural concrete properties research or structural design, and may be able to provide information for the SMIC. These contacts and the provided reports will be surveyed for input to the SMIC. 


\subsubsection{Expent_Systems}

The results of the development of a structural condition assessment methodology may eventually be documented in an Expert System. An Expert System is an electronic version of the collected knowledge and experience of experts in a particular field. The electronic database of the Structural Materials Information Center will be designed to function as the database for an Expert System, should such be required in future development under the SAG Program.

3.2.3.1 DURCON. Description - DURCON is a prototype expert system being developed by the National Institute of Standards and Technology.D.5 It is designed to give recommendations on the selection of constituents for durable concrete. It is a development activity demonstrating the application of expert systems. Four major deterioration problems are addressed: (1) freezing and thawing. (2) corrosion of reinforcing steel. (3) sulfate attack, and (4) alkali-aggregate reactions.

Considerations for Structural Materials Information Center (SMIC) Use - The most demanding tasks in the developing of an expert system are the obtaining, verification, and representation of the relevant knowledge. Advances made by DURCON in these tasks are expected to provide valuable information and guidance for both the SMIC and the condition assessment methodology phase of the SAG Program.

3.2.3.2 IKSMAT. Description - IKSMAID.25 is an expert system being developed by Material Property Databases. Inc., an MPD Network associate, for the U. S. Air Eorce. It is still at the preliminary study level. but an on-line demonstration interface has been developed. The features of the IRSMMAT system, in addition to the underlying material property databases, are:

1. a knowledge base of material selection and design criteria, criteria priorities and weights, and interactive access of these elements with the system controller and the databases.

2. materials selection for specified components, addition of new materials and properties into the analysis, modification of selection and search criteria.

3. the ability to deal with design related parameters such as critical crack size under specific conditions and other criteria comparisons across material classes, and

4. cross checking of application limitations such as are found in specifications. 
Considerations for Structural Materials Information Center ( SMIC) Use - An additional feature claimed for the IKSMAT system is its flexibility with regard to broad applicability to other components and other fields of engineering and material science. This may indicate usefulness in the condition assessment methodology phase of the SAG Program.

3.2.3.3 Expert System on the "Repair of Concrete Structures". Description - The existence of this system was mentioned in the response from Deutscher Beton-Verein (DBV).S.11 The contact is Prof. Reinhardt, Technische Hochschule. Petersenstr. 15, 6100 Darmstadt. Nothing more is presently known about this system than is described in its title.

Considerations for Structural Materials Information Center (SMIC) Use - Additional information will be requested on this system so that an assessment of its potential application to the SAG Program can be made.

3.2.3.4 CRACKS. Description - CRACKSD.46 is an expert system for diagnosing the cause of cracks in concrete. The system is being developed at the National Institute of Standards and Technology and combines structural imaging (optics) with structure and service data.

Considerations for Structural Materials Information Center (SMIC) Use - Developments of this expert system will be monitored by SAG Program personnel for its potential use in condition assessment of concrete structures in nuclear power plants. 


\section{CONCLUSIONS AND RECOMMENDATIONS}

\subsection{Concrete Materials Databases}

The survey conducted during this study produced some references that report on the properties of concrete under nuclear power plant conditions. The applicable data from these reports will be extracted and placed into the Structural Materials Information Center. However, the information obtained in this review generally supports the conclusion reached elsewhere, that data on the aging of concrete materials are very limited.D.1 The search for applicable data will continue, and will be supplemented by the appropriate tests, under the direction of the SAG Program.

\subsection{Hardware}

It is recommend that the development of the Structural Materials Database be directed toward applications using the IBM Personal Computer and compatibles. This recomendation is based on the ready accessibility of this system to most engineers, and the wide availability of software. The use of PCs was also judged to be the most economical approach.

\subsection{Software}

A "Standard" database or database management system designed specifically for a wide variety of structural materials. or concrete in particular. could not be located. As stated at the beginning of this report, the next best solution was to locate a "Customized Standard" database or database management system which could be modified relatively easily to accomodate structural materials information. Accordingly, it is recommended that the database software MatDB, produced by ASM International, be chosen to develop the Structural Materials Database. Of all the database and database management system products examined for the PC. this software appeared to be the best suited for a structural materials database, and most effectively retains the option to easily connect with a mainframe network. In addition, choosing a "canned" commercial database avoids the appreciable development effort and costs associated with a custom built system.

\subsection{Network Systems}

Networking the Structural Materials Information Center (SMIC) should be a continuing option. Networks can provide an economical way to access state-of-the-art materials information. In addition, networking simplifies and accelerates the distribution process for updates to the database file, since the information is concentrated in one centrally located file. New information is accessed directly by authorized 
users, rather than having to be reproduced on magnetic disks or on paper for later distribution through the mail system.

One good method for keeping the network option open and at the same time gain valuable input for the SMIC, whether retained as a purely local system or not. would be to maintain contact with the MPD Network activity. This will be dore at the professional level by the SMIIC project members, but participation as a supporting member should be considered by the USNRC, for the reasons given above in the discussion of the MPD Network.

\subsection{Euture Plans}

Development of a Structural Materials Information Center (SMIC) will be initiated. A report will be drafted describing the system being developed. Formatting for the Structural Materials Database and the concrete materials handbook (CMBB) " will be developed and entering of data initiated. Related database sources will be reviewed for data appropriate for extraction and entry into the SMIC. Preparations will be initiated for obtaining and testing samples from facilities subjected to representative environmental stressors (Shippingport. Humbolt Bay. Dresden I, LaCrosse, etc.). In addition, accelerated aging techniques will be investigated as a potential means for supplementing the limited database.

\subsubsection{Liaison Organizations and Activities}

Over the past several years, mumerous workshops,D.4 studies, and reports have attested to the immense interest in electronic DBs for use in government, industry, and academia. These activities have revealed a need for interaction among the designers, producers and users of databases, and cooperation on an international scale has resulted. Standards groups have been. or are being, establishedD.6.D.8 that draw on the ideas coming from this cooperation. The Structural Materials Information Center activity will establish and maintain contacts with the appropriate groups in order to benefit from developing database designs and to promote compatibility with other databases. A brief review and the potential application of some of these groups to the Structural Materials Database activity follow.

4.5.1.1 ASTM Committee E49. At present, no comprehensive standards exist for entering materials properties data into electronic databases. D.6 The American Society for Testing Materials (ASTM) established Committee E49 on Computerization of Material Property Data in 1986 to promote knowledge and to develop standard classification.

"The CMHB will be one of several chapters in the Structural Materials Handbook (SMHB) being developed. Each chapter in the SMHB will pertain to a different material system. 
guides. practice and terminology for building and accessing material property databases. To date, five subcommittees have been formed, addressing the Identification of Materials, Reporting of Test Results, Terminology. Data Interchange, and Data and Database Quality. Many Task Groups addressing specific materials, processes and other areas augment the subcommittees.

ASTM Committee B49 will establish the standards to be used in the operation of materials databases, and for this reason, participation by the Structural Materials Information Center activity should be a high priority. Initial emphasis has been on traditional metals and alloys. but the committee's scope is being expanded to include other materials such as cements and concrete. The Structural Materials Information Center presently participates in $\mathrm{B} 49$ through the standards representation procedure at the ORNL.

4.5.1.2 CODATA. CODATA is a European based interdisciplinary scientific committee of the International Council of Scientific Unions. Its stated goals are to improve the quality, reliability, processing, management and accessibility of evaluated data of importance to science and technology. The CODATA Task Group on Materials Database Management (TG/MDM) is developing operational guidelines for the builders, maintainers and distributors of materials databases. It compiles and distributes information on worldwide materials data source activities, and fosters comminication among these activities.

The TG/MOM is preparing a bulletin entitled "Guidelines for Materials Database Management." The document is designed to aid database builders, maintainers and distributors in the establishment of practices which will promote quality and reliability. This and other bulletins to come from the TG/MMM will contain information of potential help to the Structural Materials Information Center. Efforts to get on the TG/MDM mailing list will be made. Another of the methods CODATA uses to promote its interests is the sponsorship of international conferences. The next conference is to be held July 15-19, 1990, in Columbus, Ohio. The Structural Materials Information Center should send at least one representative to this conference to obtain state-of-theart information on materials properties databases.

\subsubsection{Choose So ware and Hardware}

Analysis of the available software and hardware systems will continue, with a special emphasis on the systems recommended above. This analysis will result in the choice of the systems to be developed for the Structural Materials Information Center, during the second quarter of Fiscal Year 1989. 


\subsubsection{Finalize Formats}

The format for the Structural Materials Database (electronic version) and Structural Materials Handbook (hardcopy version) will be finalized to compliment the operation of the Structural Materials Information Center (SMIC). Structured analysis, a tool of the systems designer that uses special working tools to build a document made up of data flow diagrams, data dictionaries, structured English process descriptions, and data structure diagrams, will be used. A data flow diagram, which is the first step in a structured analysis of the data system, is shown in Fig. 1. It shows the first-level steps in the development of the SMIC and illustrates the elements of the database development and the proposed divisions (Volumes 1,2, 3, and 4) of the SMIC.

\subsubsection{Collect. Eyaluate and Distribute Data}

The collection, evaluation, and distribution of information for the Structural Materials Information Center (SMIC) will proceed according to the schedule established in Ref. D.45. The information sources identified in this report will be investigated further to ascertain if there are data of value to the SAG Program, and the search for other sources will continue. The SMIC will work with the other activities in the SAG Program in the determination of materials properties requirements, planning of the materials testing programs, and evaluation and reporting of the test results. 


\section{REHEERENCES}

\subsection{Document References}

D.1. D. J. Naus, Concrete Component Aging and Its Significance Relative to Life Extension of Nuclear Power Plants, NUREG/CR4652, ORN/TM-10059, September 1986.

D.2. D. R. Benigni. Editor, Benchmark Analysis of Database Architectures: A Case Study, U.S. Department of Commerce. National Bureau of Standards, NBS Special Publication 500-132, October 1985.

D.3. MATUS - Materials User Service, The Engineering Information Company Itd, 15/17 Ingate Place, Iondon SW8 3NS.

D.4. J. H. Westbrook and I. R. McCreight, "Computerized Aerospace Materials Data." Proceedings of a Workshop on Computerized Property Materials and Design Data for the Aerospace Industry, El Segundo, CA, June 23-25. 1986.

D.5. J. R. Clifton and B. C. Oltikar, "Expert System for Selecting Concrete Constituents," Computer Applications in Concrete Technology. ACI Special Publication No. 98. SP-98-2, American Concrete Institute, Detroit. 1987.

D.6. H. Krockel, K. Reynard, and J. Tumble, Factual Materials Databanks. The Need for Standards. VAMAS Technical Working Area 10. Versailles Project on Advanced Materials and Standards. July 1987.

D.7. J. G. Kaufman, The National Materials Property Data Network: Responce to a Critical Need. AIChE Sysposium Series, Number 247. Volume 82. 1986.

D.8. J. G. Kaufman, "Towards Standards for Computerized Materials Property Data and Intelligent Knowledge Systems," ASTM Standardization News, March 1987, pp. 38-43.

D.9. V. E. Hampel. The 'TIS' Intelligent Gateway Computer, an Overview and Demonstration. Technology Information System. Lawrence Iivermore National Iaboratory. April, 1983.

D.10. W. Grattidge, et. al.. Materials Information for Science and Technology (MIST): Project Overview, NBS Special Publication 726. U.S. Department of Commerce, Washington, DC, November, 1986. 
D.11. J. T. Fong, What is DATAX?, DATAX Bulletin No. 1. American Society of Mechanical Engineers Committee on Software Research. November 1984.

D.12. J. T. Fong, "Computer Software Needs of Materials Property Databases for Selected Engineering Applications," ASME-MPC Symposium. An On-Iine Materials Property Data Base. ASME Winter Anmual Meeting. November 15, 1983.

D.13. N. M. Greene, G. F. Flanagan, and H. Alter, "Status of SACRD: A Data Base for Fast Reactor Safety Computer Codes," Trans. Am. Nuc. Soc.. Vol 43. pp 430-431, November 1982.

D.14. H. C. Honeck, The JOSHIAA System, DP-1380, April 1975.

D.15. "Metals Information," ASM International, Metals Park, OH.

D.16. E. Messmer, and D. ben-Aaron, "On-Iine Databases Turn A PC Into A Complete Library." Information WBER. August 3. 1987.

D.17. MPD Network Newsletter. The National Materials Property Data Network. Inc.. P.O. Box 02224, Columbus, OH 43202. September, 1988.

D.18. J. G. Kaufman, "The National Materials Property Data Network. Inc.. A Cooperative National Approach to Reliable Performance Data." to appear in the Proceedings of the First International Symmosium on Computerization and Networking of Materials Property Data. Philadelphia. PA, November 2-4. 1987.

D.19. B. Krasnoff, and J. Dickinson, "Project Data Base II." PC Magazine, June 24. 1986.

D.20. D. Crabb. "Relational High End Databases," Info World. April 18. 1988.

D.21. SAE Global Mobility Database and Standards Search. Society of Automotive Engineers. Inc., 400 Commonwealth Drive, Warrendale, PA 15096.

D.22. Information Handling Services. Englewood, $\infty$.

D.23. C. J. M. Northrup, Jr., J. L. McCarthy, J. H. Westbrook, and W. Grattidge, "Materials Information for Science and Technology (MIST): A Prototype Material Properties Data Network System," Proceedings of the Pressure Vessel and Piping Division and Computer Engineering Division Meeting of the American Society of Mechanical Engineers, Chicago, July 20-25, 1986. 
D.24. J. Rizzo, "Soft PC." MacUser, February 1989, pp 199-201.

D.25. MPD Network Newsletter, The National Materials Property Data Network, Inc., P.O. Box 02224. Columbus, OH 43202, April . 1988.

D.26. "CAMS: Computer-Aided Materials Selection," Advanced Materials \& Processes, Incorporating Metal Progress, ASM International. Vol. 2, No. 1, Mid-June 1987, pp 7-24.

D.27. J. T. Fong, "Engineering Databases: Software for On-Line Applications." The 1984 PVP Conference \& Exhibit of The American Society of Mechanical Engineers, San Antonio. Texas, June 1721. 1984 .

D.28. U. Schneider, "Verhalten von Beton bei hohen Temperaturen Behaviour of Concrete at High Temperatures," German Committee of Reinforced Concrete Brochures, HEFT 337, 1982.

D.29. J. Seeberger. J. Kropp, and H. K. Hilsdorf, "Festigkeitsverhalten und Strukturveränderungen von Beton bei Temperaturbeanspruchung bis $250^{\circ} \mathrm{C}$." German Committee of Reinforced Concrete Brochures, HEFT 360, 1985.

D.30. Strength Tests of Concrete Subjected to Elevated Temperatures, MUU-0248, PNC TN241 85-07.

D.31. Integrity Test on Primary Containment System (IV), MJU-0291. ENC SJ222 81-01.

D.32. Structural Integrity Test of Typical Floor Liner System for MONUJ Fast Breeder Reactor Plant. MJU-0292. PNCSJ222 82-03.

D.33. Concrete Experiments for Structural Integrity Verification of MONUU, Fast Breeder Reactor. MJU-0398, PNC SJ299 83-13.

D.34. Experiments for Measurement of Concrete Thermal Expansion Coefficient for Structural Integrity Verification of MONUU, Fast Breeder Reactor, MJU-0399. FNC SJ299 83-16.

D.35. Thermal Diffusivity Coefficient Measurement Tests of Concrete Materials for Structural Integrity Verifgication of Reactor Building for Fast Breeder Reactor. MONJU, MJU-0400, PNC SJ299 83-18.

D.36. Tsutomu Kanazu. Mechanical Properties of Concrete and Reinforced Concrete at Elevated Temperatures over $100^{\circ} \mathrm{C}$. High Temperature Concrete, 1986 EPRI/CRIEPI Joint Study Report. September 1987. 
D.37. T. Kanazu, H. Ishida, and T. Endo, "Estimation of Deformational Behaviour of Reinforced Concrete Beams with Axcial Force at High Temperature," Trans.Japan Concrete Institute, 1987.

D.38. T. Kanazu, Y. Aoyagi, and T. Endo, "Infulence of Axial Forces and Area of Reinforcement on Mechanical Behaviour of Reinforced Concrete Members at Elevated Temperatures." Trans. Japan Concrete Institute. 1986.

D.39. T. Kanazu, Y. Aoyagi, T. Endo, and M. Oshima, "Mechanical Behaviors of Reinforced Concrete Members at Elevated Temperatures," Trans. Japan Concrete Institute. 1985.

D.40. T. Kanazu, Y. Aoyagi, and R. Satoh, "Evaluation of Steel Stresses and Crack Widths of Reinforced Concrete Members under Temperature Gradients," Trans. Japan Concrete Institute, Vol. 3 1981.

D.41. T. Kanazu, and Y. Aoyagi. Mechanical Behaviour of Concrete and Reinforced Concrete at Elevated Temperatures up to $500^{\circ} \mathrm{C}$. 8th SMiRT, H 5/1. pp 193-198.

D.42. HIMIAC/CINDAS, Purdue University, "HIMIAC Providing On-Line Numerical Database Service to the DoD," HIMIAC Newsletter, December 1987.

D.43. M. A. Dibble, "Databases Simplity the Materials Search." Machine Design. August 11, 1988, pp 100-103.

D.44. J. Gilman, "Computerized Materials Data at EPRI." pp. 12-14 in Computerizing Materials Data - A Workshop for the Nuclear Power Industry. May 2-3, 1984. NBS Special Publication 689.

D.45 D. J. Naus et al.. Structural Aging (SAG) Program. Five-Year Plan: FY 1988-1992, ORN//NRC/LTR-89/1, Martin Marietta Energy Systrems, Inc., Oak Ridge Natl. Lab., February 1989.

D.46 J. R. Clifton and L. J. Kaetzel. CRACKS - An Expert System for Diagnosing the Cause of Cracks in Concrete. National Bureau of Standards. Gaithersburg. MD. August 1987.

\subsection{Source References}

S.1 N. M. Greene, Personal Comminication, Oak Ridge National Laboratory. Jamuary 6. 1989.

S.2. B. Mather, Personal Communication, U. S. Army Engineer Waterways Experiment Station, Vicksburg, MS, May 19, 1988. 
S.3. A. Kao, Personal Commuication, Construction Engineering Research Laboratory, Champaign, II. June 9. 1988.

S.4. B. Sheetz, Personal Commication, Materials Research Laboratory, Penn State. University Park. PA, May 20, 1988.

S.5. J. G. Kaufman. Personel Comminication. The National Materials Property Data Network. Inc., P.O. Box 02224. Columbus, OH, October 20. 1988.

S.6. H. K. Hilsdorf and H. S. Miller, Universität Karlsruhe (IH), Institut für Massivbau und Baustofftechnologie. Am Fasanengarten, D-7500 Karlsruhe 1, Federal Republic of Germany, Letter to M. F. Marchbanks, November 14. 1988; Subject: Materials Properties Database for Concrete Materials.

S.7. Shuichi Iwata, University of Tokyo, Department of Nuclear Engineering, Bunkyo-Ku, Tokyo, Japan, letter to M. F. Marchbanks. August 17. 1988: Subject: Concrete Databases in Japan.

S.8. J. W. Weber, Institut Für Bauforschung. Rheinisch-Westfälische Technische Hochschule Aachen, Dienstgebäude: SchinkelstraBe 3. D-5100 Aachen. Federal Republic of Germany, letter to M. F. Marchbanks, August 23, 1988: Subject: Materials Properties Data Base for Concrete Materials.

S.9. D. Wiendieck, Kernforschungszentrum Karlsruhe, GmbH, Postfach 3640, D-7500, Karlsruhe 1, Federal Republic of Germany, letter to M. F. Marchbanks, July 8, 1988: Subject: Materials Properties DataBase for Concrete Materials.

S.10. R. Lewandowski, IBR Institut für Bautechnologie, GmbH, Postfach 1617, 4030 Ratingen. ChristinenstraBe 20/22. Federal Republic of Germany, letter to M. F. Marchbanks, June 28, 1988.

S.11. Dr.-Ing. Hermann, Deutscher Beton-Verein E.V., Postfach 2126 , 6200 Wiesbaden 1. Federal Republic of Germany, letter to M. F. Marchbanks, July 5, 1988.

S.12. R. C. Burrow, Power Reactor and Nuclear Fuel Development Corporation, 9-13, 1-Chomr, Akasaka, Minato-ku, Tokyo, Japan, letter to M. F. Marchbanks, December 5, 1988; Subject: HighTemperature Materials Experts in Japan. 
S.13. Yukio Takashi, Komae Research Laboratgory, Central Research Institute of Electric Power Industry, 11-1. Iwato Kita 2-Chome Komae-Shi, Tokyo 201 Japan, personal communication to M. F. Marchbanks, 1988.

S.14. C. Y. Ho, Center for Information and Numerical Data Analysis and Synthesis. West Lafayette. Indiana, personal comminication to M. F. Marchbanks, January 1989. 
Table 1. DBMS software summary

\begin{tabular}{|c|c|c|c|c|c|c|c|c|}
\hline \multirow[b]{2}{*}{$\begin{array}{l}\text { Program } \\
\text { name }\end{array}$} & \multirow[b]{2}{*}{$\begin{array}{c}\text { Mainframe } \\
\text { DBMSa }\end{array}$} & \multirow[b]{2}{*}{$\begin{array}{l}\text { PC } \\
\text { DBMS }\end{array}$} & \multicolumn{3}{|c|}{ Type of software } & \multirow[b]{2}{*}{$3 \mathrm{GL}^{2}$} & \multirow[b]{2}{*}{ 4GL ${ }^{a}$} & \multirow[b]{2}{*}{ Cost $b$} \\
\hline & & & $\begin{array}{c}\text { SMDBa }^{2} \\
\text { standard } \\
\text { software }\end{array}$ & $\begin{array}{c}\text { SMDB }^{a} \\
\text { customized } \\
\text { standard } \\
\text { software }\end{array}$ & $\begin{array}{c}\text { SMDBa } \\
\text { customized } \\
\text { software }\end{array}$ & & & \\
\hline SPIRES & $\mathrm{X}$ & & & & $\mathrm{x}$ & & $\mathrm{X}$ & $\begin{array}{l}\$ 1,000 \text { license fee }+ \\
\$ 7,500 / \text { yr dues }\end{array}$ \\
\hline MESSENGER & $\mathrm{x}$ & & & & $\mathrm{X}$ & & $\mathrm{X}$ & $\begin{array}{l}\text { Software is unavallable } \\
\text { (proprietary) }\end{array}$ \\
\hline ORACLE & $\mathrm{X}$ & $\mathrm{x}$ & & & $\mathrm{x}$ & & $\mathrm{x}$ & $\begin{array}{l}\text { Mainframe: } \$ 150,000 \mathrm{~K} / \mathrm{yr} \\
\text { PC: } \$ 1.300+\end{array}$ \\
\hline INGRES & $\mathrm{x}$ & $\mathrm{X}$ & & & $\mathrm{X}$ & & $\mathrm{X}$ & $\begin{array}{l}\text { Mainframe: see footnote } \\
\text { PC: } \$ 1.850\end{array}$ \\
\hline MetSe12 & & $\mathrm{x}$ & & $\mathrm{x}$ & & $\mathrm{x}$ & & $\$ 550$ \\
\hline MatDB & $\mathrm{x}$ & $\mathrm{x}$ & & $\mathrm{x}$ & & & $\mathrm{x}$ & Not yet available \\
\hline dBase & & $\mathrm{X}$ & & & $\mathrm{x}$ & $\mathrm{x}$ & & $\$ 1.170$ \\
\hline Rbase & & $\mathrm{x}$ & & & $\mathrm{X}$ & $\mathrm{X}$ & & $\$ 1.090$ \\
\hline
\end{tabular}

aDBMS = database management system. SMDB = structural materials database,

3GL $=$ third-generation language, 4GL $=$ fourth-generation language.

bCost is for user only, not developer, and includes basic software and graphics, or leasing charges. Cost of INGRES on the mainframe WIN system would be included in the $\$ 1000 / y$ WIN user fee. 
Table 2. Computerized databases

\begin{tabular}{|c|c|c|c|c|c|c|c|c|}
\hline $\begin{array}{c}\text { Database } \\
\text { name }^{a}\end{array}$ & Mainframe & $\mathrm{PC}$ & $\begin{array}{c}\text { Contains mumerical } \\
\text { data of } \\
\text { interest to } \\
\text { SMIC }^{b}\end{array}$ & $\begin{array}{l}\text { Contains } \\
\text { references of } \\
\text { interest to } \\
\text { SMIc }\end{array}$ & $\begin{array}{l}\text { SMIc b } \\
\text { could } \\
\text { use } \\
\text { hardware }\end{array}$ & $\begin{array}{c}\text { SMICb } \\
\text { could use } \\
\text { software or } \\
\text { system design }\end{array}$ & $\begin{array}{l}\text { Liaison } \\
\text { activity } \\
\text { of potential } \\
\text { use to SMICb }\end{array}$ & Cost \\
\hline WIN & $\mathrm{x}$ & & & & $\mathrm{x}$ & $\mathrm{x}$ & & $\$ 1.000 / \mathrm{yr}$ \\
\hline SACRD & $\mathrm{x}$ & & & & & $\mathrm{x}$ & & $\mathbb{N A}$ \\
\hline MPD Network & $x$ & & & & $\mathrm{x}$ & $\mathbf{x}$ & $\mathrm{x}$ & $\begin{array}{l}\text { Sponsor's cost: } \\
\$ 10.000 / \mathrm{yr}\end{array}$ \\
\hline RSIC & $\mathrm{x}$ & & & $\mathrm{x}$ & & & & None \\
\hline CERL & $\mathrm{x}$ & & & & & $\mathrm{x}$ & $\mathrm{x}$ & Not determined \\
\hline MCIC & $\mathrm{x}$ & & & $\mathrm{x}$ & & & & NA \\
\hline MPDC & $\mathrm{x}$ & & & $\mathbf{x}$ & & & & NA \\
\hline MARTUF & $\mathrm{x}$ & & & & & $\mathrm{x}$ & $\mathbf{x}$ & Not determined \\
\hline EMISN & $\mathrm{x}$ & & & & & & $\mathrm{x}$ & $\mathbb{N A}$ \\
\hline Karlsruhe & $\mathrm{x}$ & & $\mathrm{x}$ & & & & & Not determined \\
\hline Univ. Tokyo & $\mathrm{x}$ & & $x$ & $\mathrm{x}$ & & & $\mathbf{x}$ & $\mathrm{NA}$ \\
\hline PID & $\mathrm{x}$ & $\mathrm{x}$ & & & & $\mathrm{x}$ & & Not determined \\
\hline EPRI & $\mathrm{x}$ & & & & & $\mathrm{x}$ & & Nbt determined \\
\hline MRL & $\mathrm{x}$ & $\mathrm{x}$ & $\mathrm{x}$ & & & $\mathrm{x}$ & $\mathbf{x}$ & Not determined \\
\hline DATAX & & $\mathrm{x}$ & & & NA & $\mathbf{x}$ & $\mathrm{x}$ & NA \\
\hline MetSe12 & & $\mathrm{x}$ & & & NA & $\mathrm{x}$ & & $\$ 550+$ \\
\hline IBR & & $\mathrm{x}$ & $\mathbf{x}$ & & NA & $\mathrm{x}$ & & Not determined \\
\hline HMIIAC & $\mathrm{x}$ & $\mathrm{x}$ & $\mathrm{x}$ & & $\mathbf{x}$ & $\mathrm{x}$ & $\mathrm{x}$ & Not determined \\
\hline MATDB & $\mathrm{x}$ & $\mathrm{x}$ & & & & $\mathrm{x}$ & $\mathrm{x}$ & $\begin{array}{l}\text { Not yet } \\
\text { available }\end{array}$ \\
\hline
\end{tabular}

aDatabases are identified in Section 3.2.1.

bSMIC = Structural Materials Information Center. . 
Table 3. Hardcopy databases (handbooks)

\begin{tabular}{lccc}
\hline $\begin{array}{c}\text { Database } \\
\text { name }^{a}\end{array}$ & $\begin{array}{c}\text { Contains numerical data } \\
\text { of interest to } \\
\text { SMIC }^{b}\end{array}$ & $\begin{array}{c}\text { Contains references } \\
\text { of interest to } \\
\text { SMICb }\end{array}$ & $\begin{array}{c}\text { Liaison activities } \\
\text { of potential use } \\
\text { to SMICb }\end{array}$ \\
\hline CTIAC & $\mathrm{X}$ & $\mathrm{X}$ & $\mathrm{X}$ \\
ACI & & $\mathrm{X}$ & \\
IBAC & $?$ & $?$ & $\mathrm{X}$ \\
KFS & $\mathrm{X}$ & $\mathrm{X}$ & $\mathrm{X}$ \\
DBV & $\mathrm{X}$ & $\mathrm{X}$ & \\
Japan & & & \\
\hline
\end{tabular}

a Databases are identified in Section 3.2.2.

$b_{\mathrm{A}}$ question mark (?) indicates further contact should be made to determine value. SMIC $=$ Structural Materials Information Center. 


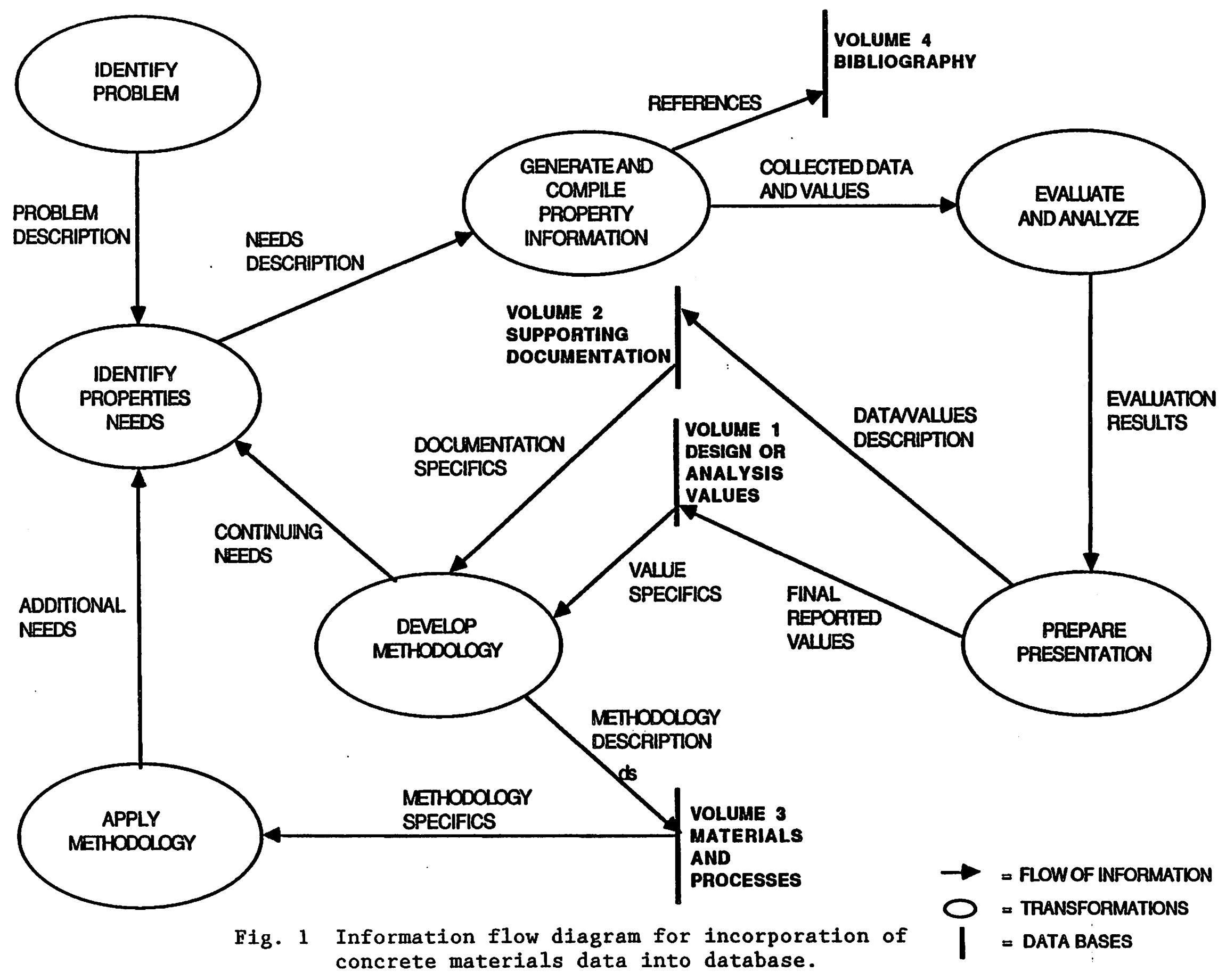


ORNL/NRC/LTR-89/3

\section{Internal Distribution}

1. W. L. Cooper

2. J. M. Corum

3. D. M. Eissenberg

4. A. P. Malinauskas

5-7. M. F. Marchbanks

8-12. D. J. Naus

13-15. C. B. Oland
16. J. G. Pruett

17. C. E. Pugh

18. G. C. Robinson

19. H. E. Trammell

20. D. B. Trauger

21. A. Zucker

22. Laboratory Records, R.C.

\section{Extema1 Distribution}

23. G. A. Arlotto, Division of Engineering, Office of Nuclear Regulatory Research. Nuclear Regulatory Commission. Washington, DC 20555

24-28. E. G. Arndt, Division of Engineering, Office of Nuclear Regulatory Research, Nuclear Regulatory Commission, Washington, DC 20555

29. J. F. Costello, Division of Engineering, Office of Nuclear Regulatory Research, Nuclear Regulatory Commission, Washington, DC 20555

30. W. S. Farmer, Division of Engineering, Office of Nuclear Regulatory Research. Nuclear Regulatory Commission, Washington, DC 20555

31. H. Graves, Division of Engineering, Office of Nuclear Regulatory Research. Nuclear Regulatory Commission, Washington, DC 20555

32. A. Murphy, Division of Engineering, Office of Nuclear Regulatory Research. Nuclear Regulatory Commission, Washington, DC 20555

33. W. Norris, Division of Engineering, Office of Nuclear Regulatory Research. Nuclear Regulatory Commission, Washington, DC 20555

34. J. Philip. Division of Engineering, Office of Nuclear Regulatory Research, Nuclear Regulatory Commission, Washington, DC 20555

35. M. Vagins, Division of Engineering, Office of Nuclear Regulatory Research, Nuclear Regulatory Commission, Washington. DC 20555

36. J. P. Vora, Division of Engineering, Office of Nuclear Regulatory Research, Nuclear Regulatory Commission, Washington, DC 20555 
